\title{
An Evaluation of Grade Six English Curriculum of Beaconhouse School System in Pakistan
}

\author{
Muhammad Tauseef \\ Dept. of Applied Linguistics, Government College University Faisalabad, Pakistan \\ Tel: 92-300-9551933Ｅ-mail: englischolar@gmail.com
}

Syed Kazim Shah (Corresponding author)

Dept. of Applied Linguistics, Government College University Faisalabad, Pakistan

Tel: 92-302-5652104Ｅ-mail: kazimkazmi@gmail.com

Fatima Tul Zahra Sulehri

Dept. of English Language and Applied Linguistics, AIOU Islamabad, Pakistan

Tel: 92-313-8711933Ｅ-mail: fatimatulzahra29@gmail.com

Mehwish Kalsoom

Dept. of Applied Linguistics, Government College University Faisalabad, Pakistan

Tel: 92-304-1690105Ｅ-mail: mehwish.maz@gmail.com

Received: May 19, 2015 Accepted: June 13, 2015 Published: June 15, 2015

doi:10.5296/ijele.v3i2.7824 URL: http://dx.doi.org/10.5296/ijele.v3i2.7824

\begin{abstract}
Curriculum and instruction material are considered fundamental tools in ELT throughout the world. Consideration of utmost significance of the curriculum requires its evaluation process for measuring its effectiveness in facilitating teaching/learning objectives. The present study is an attempt to evaluate grade six English curriculum of Beaconhouse School System. To the end, features based on the objectives of the curriculum were evaluated to determine whether learning of language, listening, reading, speaking, and writing, vocabulary and understanding
\end{abstract}


of grammar, literature (both fictional and non-fictional), personal understanding and global perspective, composition and presentation skills, punctuation, spelling, handwriting, critical thinking, cultural identity and interdisciplinary links with other subjects have their particular relevance to the curriculum, textbook and the workbook used at this level. The evaluation was carried out through a checklist specifically designed to meet the situation to find out whether the curriculum and related course books are based on curriculum objectives. The present study is both qualitative and quantitative. The qualitative aspects were analyzed by careful assessment of course book through checklist items. The quantitative data was analyzed using SPSS 13.0 (Statistical Package for Social Sciences) which revealed the results that except few, curriculum was effectively facilitating the attainment of most of its teaching/learning objectives.

Keywords: Curriculum evaluation, textbook, objectives, English, grade six, Beaconhouse 


\section{Introduction}

Language varies according to different cultures and notions of the human beings. Human beings in order to profit from the shared legacy of science, technology and social growth need language. Language is required to gain the collective outcome in both dialogue and in print. In addition, a common source demands for altering the massive world into a tiny sphere where the human race communicate and share their ideas, information and knowledge. Interestingly, the language of such common source is English.

English is spoken in several countries of the world at present. It was considered as a monolithic whole as only British were the people who spoke it in long run in the past. After that, it was the industrial revolution which uplifted its need at large by adding several technological terms to the language when many people were still living primitive life. People from all around the world (e.g. Italy, Spain, France etc.) were forced to move to United States due to revolution and poverty in eighteenth century. It was the time when they adopted English through natural assimilation. According to Crystal (1997), English is spoken by over two billion people around the globe. He further states that native speakers are less than non-native speakers as English has spread across the countries of the world.

English is used in multiple domains including teaching and learning. Teaching and learning are majorly being conducted in English language by universities and colleges across the globe (Flowerdew \& Peacock, 2001; Lauder, 2008). English in education has extended its use in Pakistan rapidly over the time.

English is the official language of Pakistan. It is used in all domains of power, government, bureaucracy, military, judiciary, commerce, media, education and research at the highest level. Because it is empowering to learn English, people all over the country are ready to invest in it for the future of their children (Rahman, 2005).

Since, English is considered as a second language in Pakistan, it is generally learned in schools and other educational institutes. In fact, the effective teaching and learning of English has attained reflective interest in the field of educational planning. Government allocates a large part of energies and capital for this purpose every year. For this reason, the researchers are interested to investigate the effectiveness of English language curriculum in the context of Pakistani schools.

Curriculum is often one of the main concerns in the language classroom. In order to evaluate the effectiveness of English language curriculum in Beaconhouse School System (BSS) in Pakistan, two major components (i.e. goals and content) of English language curriculum are taken into consideration. The results of the present study will be of great potential to solve language related problems in the area. 


\section{Theoretical Background}

\subsection{What is Curriculum?}

Curriculum is often considered as a main concern in education filed. What choices teachers and education planners should offer to the learners for selection of content and methods to achieve desired learning goals? Parents always have a desire to know what their children are going to study. Learners are also concerned about knowing the content they are going to study in classroom. Curriculum is regarded as something which teachers are going to teach and learners are going to learn. Indeed, it is related to the outcome of learning process.

Goodson (1994) describes curriculum "as a multifaceted concept, constructed, negotiated and renegotiated at a variety of levels and in a variety of arenas" (p. 111). This view reflects the complex and interactive nature of curriculum. Curriculum consists of a plan of learning which is composite of some main and secondary components. The main component of the curriculum is its goal or aim. Learning is of no importance without this component. In addition, content is the second required component of the curriculum. It is always essential to teach a selected content in order to achieve desired goals. In other way out, learning process cannot be accomplished without content. It is vital to have content as competence and effectiveness of learning closely depend on it. The method is the third component which is needed to teach or learn the content. If the method is appropriate to the learning it will be more effective. In fact, theory is transformed to practice with the use of teaching method. The evaluation is the fourth one. However, problem regarding lack of learning situations and results among planners, learners and teachers are the major deficiencies of curriculum planning. Curriculum has other factors based on the main components. The effectiveness of secondary components depends on the quality of main components. These include images, photos, tables, regulations, and other designs which influence main components and reinforce learning process. (Maleki, 2009).

\subsection{Curriculum Evaluation Models}

Cunningsworth (1995) and Ellis (1997) have suggested that there are three different types of material evaluation. They assert that the most common form is probably 'predictive' or 'pre-use' evaluation that is designed to examine the future of potential performance of a textbook. The other type of textbook evaluation are the 'in-use' evaluation designed to examine material that is currently being used and 'retrospective' or 'post-use' (reflective) evaluation of a textbook that has been used in any respective institution. The present study will examine the textbook as a curriculum through 'predictive' or 'pre-use' evaluation using an established checklist in order to see the effectiveness of the content.

Different textbook evaluation models have been presented in order to evaluate English textbooks during the last three decades. Most of the models propose criteria or design certain principles for evaluation. Tucker (1975), Sheldon (1988), Ur (1996), and Littlejohn (1998) are the noteworthy applied linguists. In the following it (i.e. Table 1) presents the second language curriculum evaluation (only major) checklists which were developed in three subsequent decades as in 1970s, 1980s, and 1990s (Riazi, 2003). 
Table 1. Influential textbook evaluation checklists in ESL context

\begin{tabular}{|c|c|c|c|c|c|c|c|c|}
\hline Decade & \multicolumn{2}{|c|}{ 1970s } & \multicolumn{2}{|c|}{ 1980s } & \multicolumn{4}{c|}{ 1990s } \\
\hline Year & 1975 & 1979 & 1983 & 1988 & 1991 & 1995 & 1996 & 1998 \\
\hline Checklist & Tucker & $\begin{array}{c}\text { Daoud } \\
\text { and } \\
\text { Celce- } \\
\text { Murcia }\end{array}$ & Williams & $\begin{array}{c}\text { Sheldo } \\
\mathrm{n}\end{array}$ & Skierso & $\begin{array}{c}\text { Cunnings- } \\
\text { worth }\end{array}$ & Ur & $\begin{array}{c}\text { Little-jo } \\
\text { hn }\end{array}$ \\
\hline
\end{tabular}

Sheldon (1988) suggests that no general list of criteria can ever really be applied to all teaching and learning contexts without considerable modification. Most of these standardized evaluation checklists contain similar components that can be used as helpful starting points for ELT practitioners in a wide variety of situations.

In addition, evaluation is an integral part of teaching and learning across the world. It is a vital component of any curriculum and plays a fundamental role in determining what learners learn. Dickins and Germaine (1994) said that "evaluation is an intrinsic part of teaching and learning" (p. 4). Cunningsworth (1995) suggested that the materials selected should reflect the needs of the learner, aims, methods and values of teaching program. Ellis (1997) stated that textbook evaluation helps in teachers going further than impressionistic assessments. It also helps them in acquiring useful, accurate, systematic and contextual insights into the overall nature of textbook material.

\subsection{Curriculum in the Scenario of Pakistan}

In Pakistan, both the public and private schools are providing education to the masses. Education system is a legacy of British rule of sub-continent in Pakistan. At the time of independence (1947) both public and private schools were providing education at primary and secondary levels. Burki (1986) classified educational institutions at the time of independence into two categories.

a. Public schools and colleges managed by provincial governments or local bodies.

b. Private schools managed by charities/missionaries.

The Public sector alone especially in developing countries cannot meet the needs of quality education for rapidly growing population including Pakistan with a $2.7 \%$ population growth rate (Government. of Pakistan 2010-11), highest in the region. Government alone can't fulfill the responsibility to provide education to fast growing population. So private sector has to share this burden. (Iqbal, 2012)

At present, the Pakistani education system is categorized with reference to the medium of instruction which propounds with socio economic classes. These systems include government schools, private schools, and religious schools. Pakistani students start learning English as a compulsory subject from grade one (Rehman, 2003). English is the medium of instruction in 
private schools, and elite schools. Urdu is the most commonly used medium of instruction in public schools, mostly for non-science subjects, and the Islamic seminaries named Madrasas. (Rahman, 2009).

Rahman (2010) stated that the process of textbook evaluation and curriculum evaluation is under the consideration in Pakistan it is not yet fully developed area it is the focus of interest these days and comprises the emerging needs of educational field. This process is very systematic and care taking as it is very important area which has practical significance.

Ministry of Education, Curriculum Wing, Islamabad has the responsibility of school curricula for grade I to XII in Pakistan. In each province there is a Curriculum Bureau or Curriculum Research and Development centre (CRDC) which provides academic support to Ministry of Education, Islamabad. In order to design curriculum which is a lengthy process, Ministry has to take opinions from all regions of the country. The curriculum draft is finalized by National Curriculum Review Committee, Islamabad. Thus uniform curriculum of each subject is followed across the country.

\section{Present Research}

The planned structure of the government school system is totally based on a formalized bureaucratic style in Pakistan. The federal Ministry of Education has the authority to form educational plans and policies to be exercised in the provinces and districts by the respective provincial and local district governments. Conversely, divide in public and private schools with respect to difference in curricula is an obvious and widespread factor in the country.

The curricula of the elitist English-medium schools and the other English-medium schools are different. Let us first take the curricula of elitist schools like Beaconhouse, City School, Froebels, and so on. The books on English and Urdu (the only languages taught in these schools) are generally not of the Pakistani Textbook Boards till class IX (Rahman, 2005)

The educational system foregrounds national unity, only an equality of educational experience can promote cohesion in the society. Most of private schools use books by private publishing houses. Private publishers have to follow the guidelines given in the National Curriculum, but they have their own procedure for textbook development. They develop textbooks and present these books to Curriculum Wing $(\mathrm{CW})$ for the review and approval. The CW constitutes a National Curriculum Review Committee (NCRC) for this purpose. A new NCRC is constituted whenever a textbook or a series of textbooks are introduced (Mahmood, 2006).

On the other hand, attitude towards the use of textbook in language class varies in Pakistan and native English speaking countries. The modern teaching approaches like Communicative Language Teaching (CLT) and Task Based Language Teaching (TBLT) have reduced the role of textbooks for language teaching in English speaking countries. In contrast, language 
textbooks still play a significant role and function as part of the curriculum [in non-English speaking countries] (Halliday, 1994).

Textbook is the core material used in ESL/EFL classrooms particularly in Pakistan. "[T]he textbook is the only available Learning Material in most schools. Additional materials like teaching aids, supplementary reading materials and school libraries are virtually non-existent" (Govt. of Pakistan, 2006). Majeed (2012) points out that "[F]or English language teaching, teachers rely only on printed material in the form of textbooks. Textbooks are the only material that is being used in Pakistani language teaching class rooms at primary, secondary and tertiary level." The use of textbooks in language classrooms in Pakistan is a general tradition in private and public sector schools which highlights its (textbook's) significant role across the country. Nunan (2001) offers the view that "syllabus design is concerned with the selection, sequencing and justification of the content of the curriculum." The present study is aimed at evaluating English Curriculum for Middle School: Revised Edition for Grade Six also evaluating Oxford English an International Approach Book One which is taught at middle level in Beaconhouse School System (BSS) in Pakistan. The researchers want to investigate the features based on the objectives of the curriculum to determine whether learning of language, listening, reading, speaking, and writing, vocabulary and understanding of grammar, literature (both fictional and non-fictional), personal understanding and global perspective, composition and presentation skills, punctuation, spelling, handwriting, critical thinking, cultural identity and interdisciplinary links with other subjects are followed in the curriculum or the course book. For this purpose the present study aims to answer the following questions;

1. To what extent content of Middle School Curriculum is effective in fostering its objectives?

2. Is there any significant relationship between curriculum objectives and content of 'Oxford English an International Approach Book One'?

3. How does the Middle School Curriculum incorporate opportunities for movement, physical activities, and experiential learning situations?

4. Are the language learning activities geared towards a student's cognitive abilities, social and affective needs, and psychomotor skills?

5. Do language activities establish the language being acquired as credible means of communication in academic as well as socio-cultural activities?

\section{Research Methodology}

There are three basic methods for evaluating textbooks. Impressionistic method is the first one which analyses a textbook on the basis of general impression. The general impression would be gained by reading the blurb and the contents page and then skimming through the book to get a sense of organization, topics, layout and visuals. This method is not adequate in it but could be combined with for example the second method, which is called the checklist method. This method is systematic in the way that the criteria on the list are checked off in a 
certain order. It is also very easy to compare different materials and it is not very time-consuming compared to other methods. The third method, the in-depth method, suggests a careful examination of representative features such as the design of one particular unit or exercise, or the treatment of particular language elements. An obvious disadvantage in this method is that the selected section might not be representative of the book as a whole. For the current study, the first and the second method were used.

\subsection{Materials}

Materials used for the present study include English Curriculum for Middle School: Revised Edition for Grade Six, the Workbook and Oxford English an International Approach Book One. The researchers also used textbook evaluation checklist proposed by Demir and Ertas (2014).

[We] suggest an eclectic checklist by borrowing items from quite different evaluation instruments available in the literature. Initially, more than thirty ELT course book evaluation forms and checklists were determined as a result of extensive review of literature. Afterwards, items were chosen from among those checklists by putting aside several of them on a utilitarian basis, accompanied by the researchers' own items. We recommend that the resulting instrument be used by English language teachers, material developers and researchers. (Demir \& Ertas, 2014)

According to Demir and Ertas (2014) the feature items from twenty three checklists were brought together for an eclectic checklist while over thirty evaluation forms and checklists were considered. These checklists include Shatery \& Azargoon (n.d.); Litz (2005); Byrd (2001); Ersoz (n.d.); Demir \& Ertas (2014); Razmjoo (2010); Lawrence (2011); Mukundan et al. (2011a); Cunningworth (1995); Williams (1983); Mukundan et al. (2011b); Daoud \& Celce-Murcia (1979); Rahimpour \& Hashemi (2011); Tekir \& Arikan (2007); Tok (2010); Peacock (1997); Ghorbani (2011); Halliwell (1992); Garinger (2002); Wen-Cheng et al. (2011); Tanner \& Green (1998); Abdelwahab (2013); and Skierso (1991).

The researchers of the present study had modified the checklist by keeping in view as the checklist may be inapplicable for the present context and research design. The checklist, thus, was altered according to the curriculum objectives and present situation. No course book evaluation checklist is complete in all the situations. Demir and Ertas (2014) stated that any checklist can be modified by adding or subtracting items according to the situation of a given instructional settings.

\subsection{Procedure}

The study used primarily qualitative research approach through which the content analysis of Oxford English an International Approach Book One was carried out in order to find the effectiveness of the textbook and its relationship to curriculum objectives. The major purpose 
of content analysis is to investigate basic features of the Middle School Curriculum of Beaconhouse School System (BSS). In this way, the present study is an evaluative research which study and evaluate the content of Oxford English an International Approach Book One. The features based on the objectives of the curriculum are given below;

- learning of language

- listening, reading, speaking, and writing

- vocabulary

- understanding of grammar

- literature (fictional and non-fictional)

- personal understanding and global perspective

- composition and presentation skills

- punctuation, spelling, handwriting

- critical thinking and cultural identity

- interdisciplinary links with other subjects

The quantitative research approach was also used in the form of graphs, frequencies and percentages. Thus, the present study follows both qualitative and quantitative research designs to analyze the data, for which it may be called mixed method research.

The data collected through aforementioned methods were analyzed and discussed. The data collected through checklist items were carefully examined qualitatively. The collected data regarding quantitative analysis were further analyzed using SPSS 13.0. This was done by using frequency distributions, percentages and necessary graphs. After analyzing the data results were checked and the conclusion was drawn.

\section{Results, Findings and Discussion}

\subsection{Beaconhouse School System}

Beaconhouse School System (BSS) in Pakistan is the Pakistan-based branch of an international company with the same name. It is a group of private fee-paying academic institutions located throughout 30 cities in Pakistan. BSS provides preschool education, primary education, secondary education and preparation for the international General Certificate of Education (GCE) and local Secondary School Certificate (SSC) examinations.

\subsection{Description of English Curriculum for Middle School: Revised Edition for Grade Six}

English Curriculum for Middle School: Revised Edition for Grade Six comprises of twelve units. It includes curriculum philosophy, target for each grade, continuity and progression charts for all strands, teaching methodologies for all four strands, lesson planning, guidelines for homework, assessment, differentiation: content, pocess, product, and environment, online global projects, ICT integration, schemes of work, (which includes topics from every unit of Oxford English an International Approach Book One accompanying objectives, reference pages, suggested ICT activities and cross curricular links) and time allocation for all four strands. It is designed by Fareeha Ahmed, Noreen Dogar, Zahra Saleha Ahmed, Mahey Noor 
and Sarah Haroon Sualehi in 2013.

\subsubsection{Aims and Objectives of English Curriculum for Middle School}

English Curriculum for Middle School: Revised Edition for Grade Six document aims to ensure that all students:

1. Understand the importance of learning the English language and realize that it is a reflective, life long process.

2. Communicate effectively and with confidence, become enthusiastic, responsive and knowledgeable readers, and receptive and successful writers.

3. Acquire a wide range of vocabulary, an understanding of grammar and knowledge of linguistic conventions for reading, writing, and spoken language.

4. Recognize the importance of reading Literature both for information and pleasure.

5. Write confidently and accurately, adapting their language, tone and style appropriately for a range of contexts and topics.

6. Use the English language as a tool to express facts and ideas about the world to promote personal understanding and global perspective, through speaking, listening, reading and writing.

7. Begin to use their composition and presentation skills to develop and communicate ideas using wide-ranging vocabulary, organizing and structuring effective writing style and sentence structure, diverse variety of forms, accurate punctuation, correct spelling and legible handwriting.

8. Think critically and are able to question opinions and ideas within their given context.

9. Use English to express individual and cultural identities all the while recognizing the importance of their own culture and language.

10. Are aware of and able to form interdisciplinary links with other subjects and learn the language through experience.

\subsection{Description of Oxford English an International Approach Book One}

Oxford English an International Approach Book One is for students aged 11-12 who have English as a strong second language or English as a first language. It is designed to suit a number of curriculums. The full series (e.g. from book one to four) will prepare students for the IGCSE in English as a Second Language. The author of Oxford English an International Approach Books One to Four is Rachel Redford. The writer is from England and is considered expert in the field. The present study has been conducted for class level $6^{\text {th }}$. The current book comprises of 10 units. Every unit of the book consists of four to eight variety of reading texts (e.g. myth, fiction, poetry, drama, prose, biography, autobiography and media like newspaper reports, TV, internet, film). Every unit supplement learning outcomes in the form of Experience, Read and Create comprises of multiple exercises and activities offering 
practice of language skills like grammar, vocabulary, reading and writing, listening and speaking. The variety of texts presents different countries of the world. Most of the reading text has been taken from the countries where English is native language like Britain and USA. Text is ranging from ENL and ESL to EFL countries like Australia, India, Egypt etc. representing their language and culture.

\subsection{Description of the Workbook}

It has ten, 7 to 8 page units that correspond to each of the textbook units. It includes practice activities for grammar, vocabulary and other language skills in different units.

\subsection{Data Analysis}

The tool for data collection is the checklist which is designed specifically to meet the objectives of the present study. It is divided into four sections, section (1) comprises subject and content of the curricula; section (2) comprises of skills and sub-skills while section (3) comprises the composition and presentation skills, whereas section (4) comprises practical considerations regarding curricula. Each item of the checklist is examined carefully while scrutinizing the curriculum.

\subsubsection{Subject and Content}

i. The content serves as a window into learning about the target language culture (American, British etc.)

There are multiple topics covering language and culture in the world. The content introduces British, Australian, South Asians and American culture e.g. the unit The Statue of Liberty (p. 123), and A new life in America (p. 124).

\section{ii. The subject and content of the course book is motivating.}

The subject and content of this book is motivating as a variety of different topics in this book has been introduced with interesting learning tasks. It includes the topics and further sub-topics varying in nature, (e.g. climate, wild life and changing the places) thus, providing the learner opportunity to get exposure of multiple themes.

\section{iii. There is sufficient variety in the subject and content of the course book.}

The course book comprises of several different topics regarding nature, wildlife, community etc. with supplementary sub-topics covering a wide range of subjects. Unit One describes the concept of use of 'water' by introducing topics like, Morning in the Desert (p. 6-9), including Who lives on water and The River Gypsies (p. 14-17).

Similarly, Unit Two is about 'climate' which describes the concept of climate by introducing sub-topics like Early Spring Causes Havoc for Hedgehogs (p. 29-30) and the poem Bush Fire (p. 38-39).

iv. The thematic content is culturally appropriate.

Mixed culture has been promoted in the course book. For example the topic Morning in the 
Desert (p. 7) in Unit One is in the context of Pakistan. Similarly, another topic in Unit Three Taj Mahal (p. 50) is related to Indian culture. In addition, the topics in Unit Eight Statue of Liberty (p. 123), and A new life in Australia (p. 132) are representing American and Australian cultures respectively.

$\mathrm{v}$. There is a relationship between the content of the course book and real-life situations (society)

Several topics in the course book represent real life situations. The examples include; How did people get water in the past? (p. 10), Morning in the Desert (p. 7), How is climate effecting the way people live? (p. 33), and What happens under the Earth's plates? in Unit Four.

vi. The topics and texts in the course book include elements from both local and target culture.

The topics and text in the course book include elements from both local and target culture for example, the topic Morning in the Desert (p. 7) represents Pakistani culture, and other topics like The Statue of Liberty (p. 123), and A new life in America (p. 124) represent American culture.

vii. Curriculum focuses on individual cultural identities and on the importance of one's own language and culture.

It focuses on individual cultural identities while including a range of texts from different cultures it also focuses on one's own language and culture. For instance, in Unit One, the topic Morning in the Desert (p. 7) is related to Pakistan. Whereas, in Unit Three, the topic Taj Mahal (p. 50) is in the context of Indian culture. In Unit Eight, the topics The Statue of Liberty (p. 123), and A new life in Australia (p. 132) are representing American and Australian cultures.

viii. Curriculum helps in recognition of interdisciplinary links with other subjects.

It helps in making interdisciplinary links with other subjects like 'Science', for example the topics What causes earthquakes and tsunamis? (p. 66) and What is a volcano? (p. 60).

ix. Curriculum expresses facts and ideas about the world to promote personal understanding and global perspective.

Curriculum expresses facts and ideas about the world through the topics like, How do we see others and ourselves? (p. 136) and What is the identity of a community? (p. 141) in order to promote personal understanding and global perspective. 


\subsubsection{Skills and Sub-skills}

a. Reading Skills:

\section{Reading Skills}

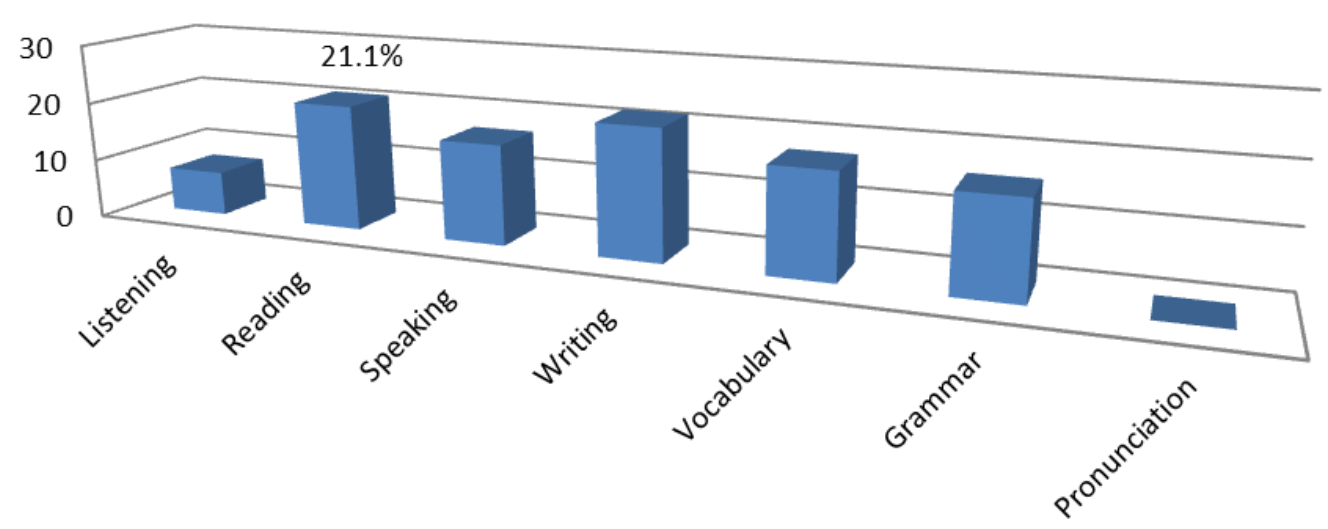

Figure 1. Reading Opportunities in the Curriculum

i. There are exercises and tasks for improving reading comprehension.

There are thirty four tasks of reading in the course book. Every unit includes these tasks e.g. reading opportunities are suggested in Unit One as 'extract and interpret the given comprehension passage: The River Gypsies' the instruction is to 'respond to the given text orally and in writing.' Further, several tasks are given (at p. 6-9, 14-17, 29-30, 34-36, 38-39 etc.) for improving reading comprehension.

ii. There is a wide range of different reading texts with different subject content.

Different reading texts with different subject content are the part of course book, examples include topics and sub-topics in Unit One to describe concept of use of 'water' by introducing topics like Morning in the Desert (p. 6-9), Who lives on water and The River Gypsies (p. 14-17).

Similarly, Unit Two is about 'climate' and it has described this concept by introducing sub-topics like Early Spring Causes Havoc for Hedgehogs (p. 29-30), and the poem Bush Fire (p. 38-39).

Unit three is about 'air' which comprises of sub-topics like Who owns the air? (p. 42-43), What is fresh air like? (p. 45), What problems come from polluted air? Similarly, Taj Mahal (p. 50-52) has been introduced in the above mentioned sub-topics. In the same way every unit of the course book contains a variety of sub-topics to describe the main theme.

iii. The reading selections are authentic pieces of language.

Mostly, the text has been taken from the native countries (e.g. Britain, America, Australia, and South Africa) which include poems, prose, biographies and many more genres, examples of which are included (on p. 6-9, 14-17, 29-30, 34-36, 38-39 etc.) in the course book. 
b. Listening Skills:

\section{Listening Skills}

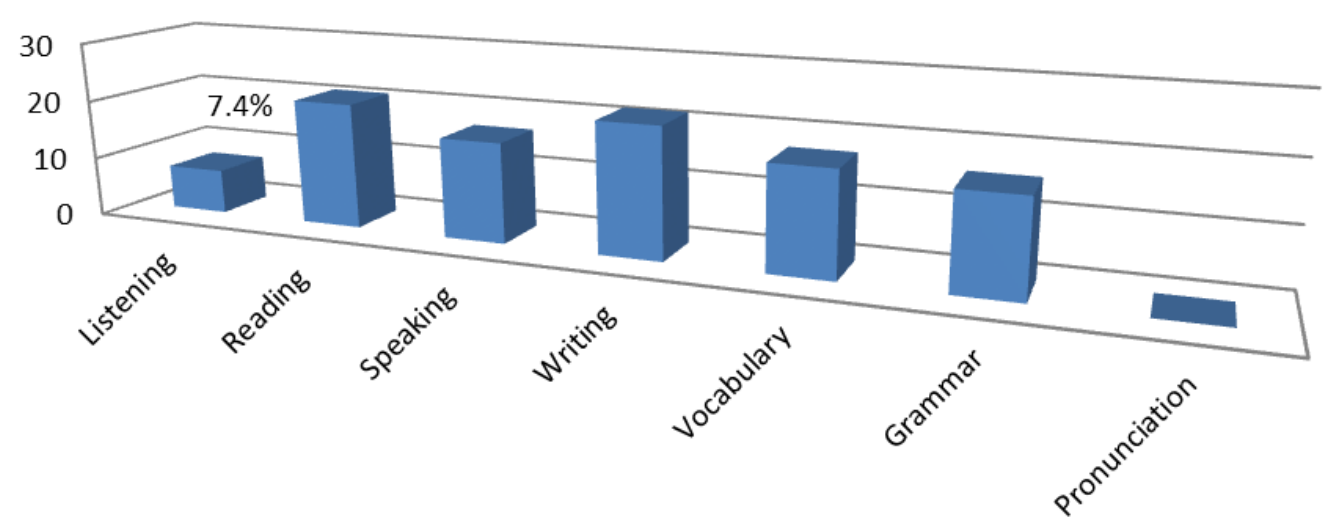

Figure 2. Listening Opportunities in the Curriculum

i. The course book has listening tasks with well-defined goals.

Listening goals are well-defined e.g. course book includes tasks to develop the ability to listen courteously to others and be sensitive to turn taking. For instance, one of the objectives of Unit Two is to 'respond constructively to others, taking different views into account and modifying them in the light of what others say' (p. 18-19).

ii. The listening material is accompanied by background information, questions and activities which help comprehension.

In the course book, listening tasks like 'discuss the talking points as whole class by responding constructively to others' and 'play a recording of the text written by Pliny the Younger and use it to make your notes' (p. 60-61) confirm that listening material is accompanied by background information, questions and activities which help comprehension. Similar examples can be found in Unit Three (p. 43); Unit Six (p. 100); Unit Eight (p. 123,135); Unit Nine (p. 148,151); and Unit Ten (p. 153, 158, 162-163) etc. 
c. Speaking Skills:

\section{Speaking Skills}

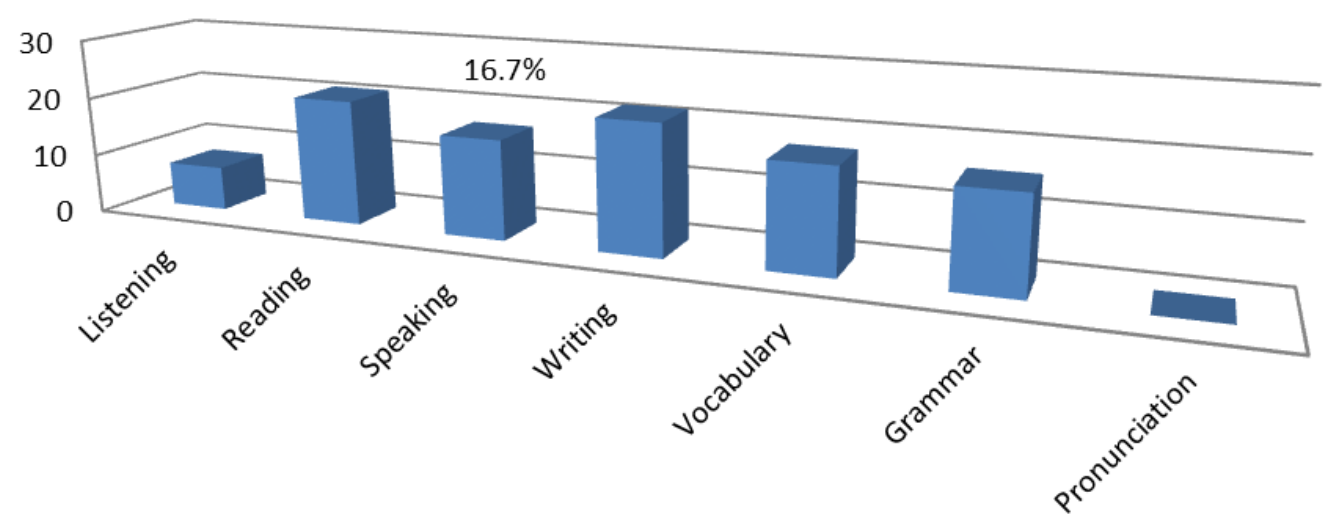

Figure 3. Speaking Opportunities in the Curriculum

\section{i. The course book includes speech situations relevant to students'background.}

The course book offers ample speaking opportunities which include speech situations relevant to students' background, for example in Unit One the tasks such as 'How water is important to you?', and 'How much of a role does water play in your daily routines?' (p. 6) signify this point as the students are familiar with the phenomenon under discussion.

\section{ii. The activities are developed to initiate meaningful communication.}

The course book, for example, offers certain activities in order to develop meaningful communication among the learners. The tasks include, "perform a role play interview based on the story of Yong and the little girl Ningnong (p. 70), 'social and cultural context: compare and contrast Dad's council elections to elections in Pakistan', 'Conducting a debate' (p. 151), and 'Engage an audience, using a range of techniques to explore, enrich and explain the key points in the poem 'Bedeh' through a discussion' (p. 18) etc.

\section{iii. The course book includes individual and group speaking activities.}

Individual and group speaking activities are included in the course book. Individual speaking activities are given in Unit One, for example, 'discuss the importance of water by using talking points' (p. 6), whereas 'Express opinions about the phenomenon of climate change by using the talking points' (p. 28), and 'present the weather forecast to the class' (p. 41) in Unit Two and the similar tasks are also given in other units.

Moreover, examples of group or shared speaking activities include, for instance, the task in Unit Six, 'discuss the talking points as a whole class which will lead to the journal entry in the writing opportunities (p. 100), and in Unit Four as, 'discuss the prompts in 'looking closely' as a whole class by responding constructively to others' (p. 66-67). 
d. Writing Skills:

\section{Writing Skills}

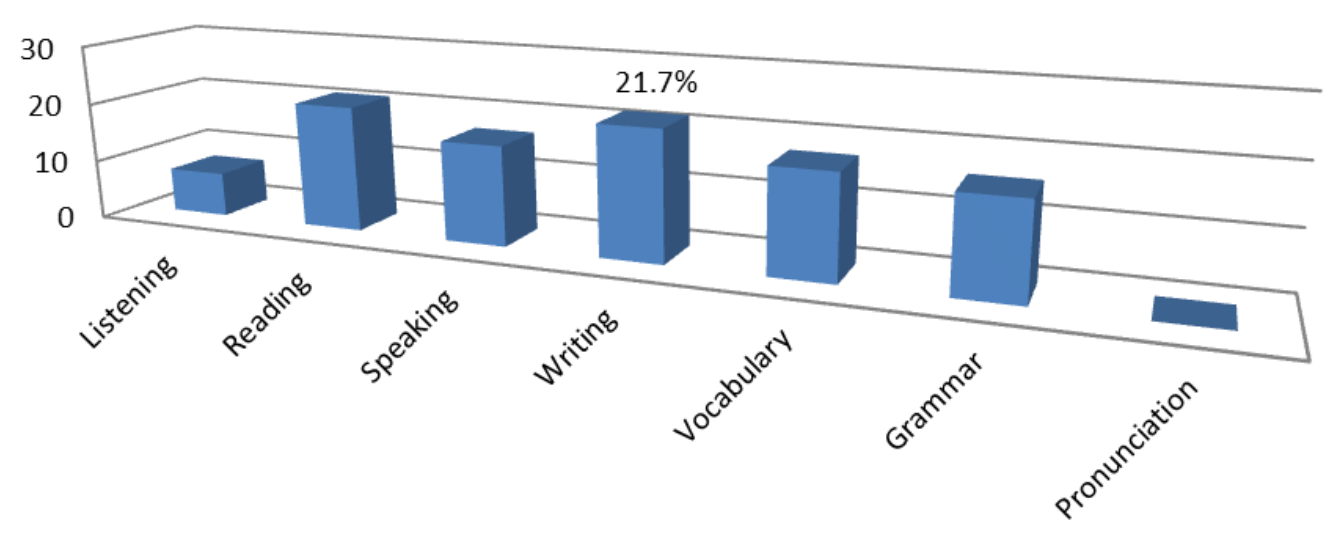

Figure 4. Writing Opportunities in the Curriculum

\section{i. Models are provided for different genres.}

Models like modeled writing, shared writing, guided writing, independent construction, and brainstorming (e.g. in writing prose, poetry, autobiography etc.) have been followed in the curriculum. Furthermore, examples of the writing tasks which follow these models for different genres are included (at p. 9, 17, 36, 57, 66, 100) in the course book.

ii. Practice is provided in controlled and guided composition in the early stages.

In the early stages, practice is provided in guided composition, for example, 'write a poem clearly and coherently, including an appropriate level of detail' (p. 40), 'plan a weather forecast report' (p. 41), and form a descriptive response to an image producing creative and thoughtful composition that interests and engages the reader' (p. 45-47).

e. Vocabulary:

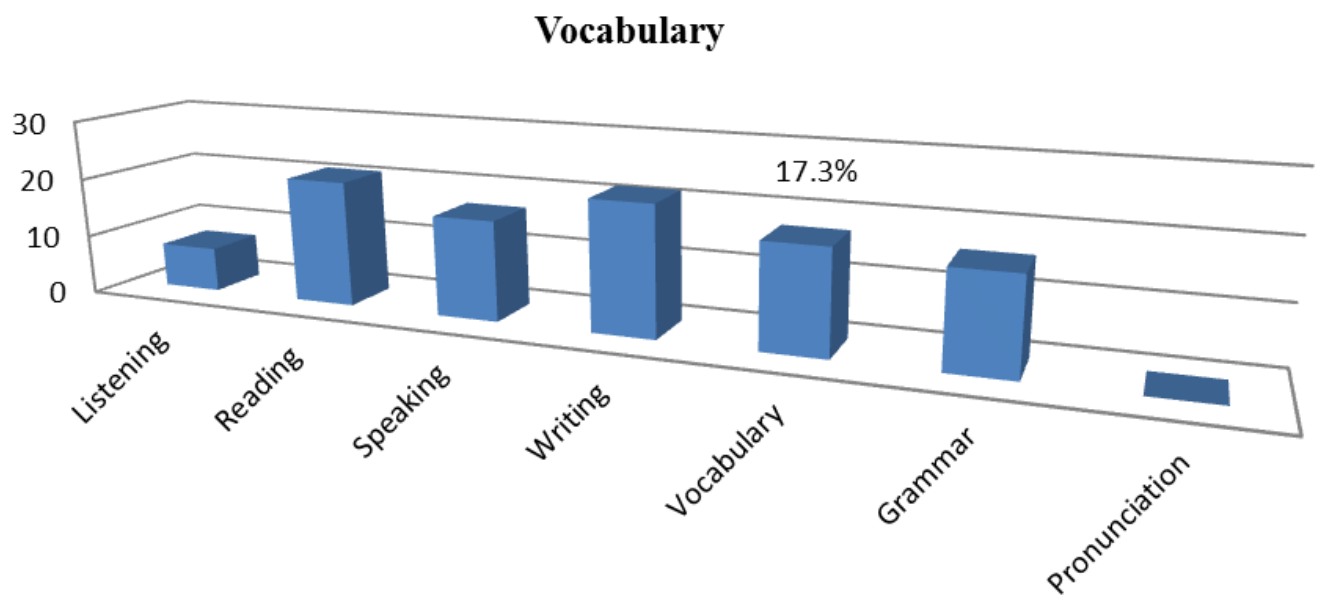

Figure 5. Vocabulary Exercises in the Curriculum 
i. The vocabulary load (i.e. the number of new words introduced in every lesson) seems to be reasonable for the students of this level.

The vocabulary load seems reasonable at this level. For instance, 'wordpool' and 'glossary' comprising almost 8 to 10 words collectively is given at the end of every topic and sub-topic. In addition, occurring of words in the text is highlighted by mentioning paragraph or line number of each occurrence in 'wordpool' which in turn help students learn the words in the context of relevant topics.

ii. There is a good distribution (simple to complex) of vocabulary load across chapters and the whole book.

It is not really distributed from simple to complex rather mixed sort of words are given across the whole book. It is, for example, 'wordpool' in Unit One comprises of words like; to awaken, to jingle, cheerfully, impatient, monsoon, scum, impurities, tunic, horizon, to preserve, to dwindle, precious (p. 8). Similarly, Unit Eight comprises of words like; fabrics, narrow, furniture, counter, bundle (p. 126).

It is examined that vocabulary depends upon the nature of text being given, as no distribution (simple to complex) of vocabulary across chapters is found.

\section{f. Grammar:}

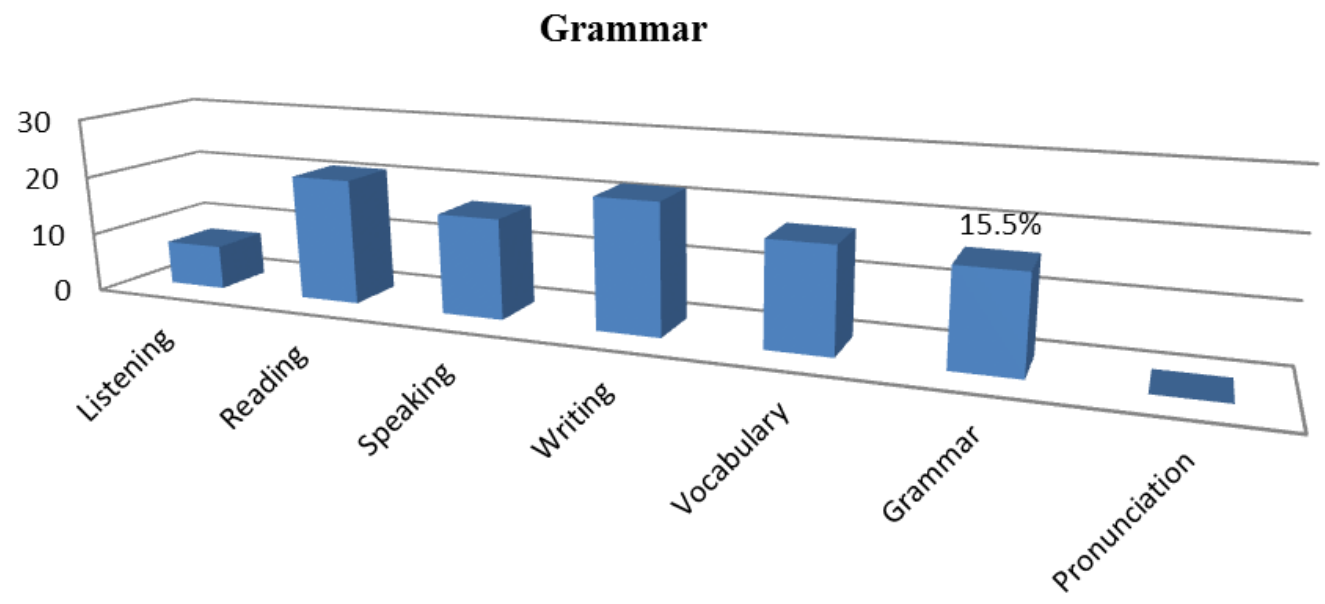

Figure 6. Grammar Exercises in the Curriculum

i. The grammar points are presented with brief and easy examples and explanations.

'Match vocabulary words to appropriate definitions in the workbook' (p. 2), and 'use different word forms and tenses in a cloze passage in the workbook' (p. 3) are the examples of the tasks in the workbook which are presented with brief and easy examples.

ii. The structures gradually increase in complexity to suit the growing reading ability of 
students.

The gradual increase in complexity of the structure has been found in the tasks. For example, 'word forms and tense' (p. 3), 'change of sentences from passive to active voice' (p. 5) and 'change of narration, direct to indirect speech' (p. 7) demonstrate an increase in the complexity of the grammatical structure.

iii. The grammar points are recycled in the following units.

The tasks like 'word forms and tense' (p. 3), 'identify and match meaning of nouns and verbs related to weather in workbook' (p. 14-15) and 'review concepts of tenses, adverbials, phrasal verbs and synonyms in the workbook' (p. 26-29) are given in the workbook which confirm that the grammar points in the workbook are recycled in the following units.

g. Pronunciation:

\section{Pronunciation}

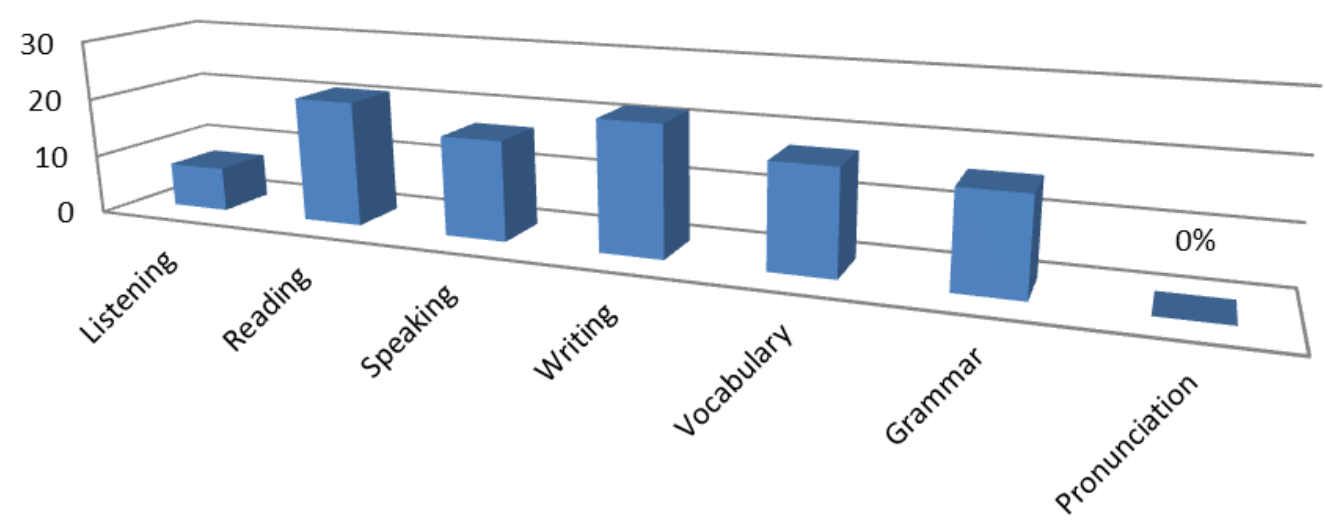

Figure 7. Pronunciation Exercises in the Curriculum

i. There is sufficient work on recognition and production of stress patterns, intonation and individual sounds.

Pronunciation tasks are not given either in English Curriculum for Middle School: Revised Edition for Grade Six or Oxford English an International Approach Book One. Pronunciation tasks are also not given in the workbook.

ii. The pronunciation points are repeated and reinforced in subsequent lessons.

Pronunciation tasks are not given either in English Curriculum for Middle School: Revised Edition for Grade Six or Oxford English an International Approach Book One. Pronunciation tasks are also not given in the workbook. 


\section{h. Sub-skills:}

i. The course book covers other sub-skills like note-taking, skimming, scanning, inferring meaning, listening for gist, etc.

The course book covers other sub-skills, examples include, 'extract and interpret the given text tiled Early Spring Causes Havoc for Hedgehogs and/or The Best Day of my Life' (p. 29-30), 'Infer and deduce meaning, recognizing the writer's intentions' (p. 34-36), and 'understand how meaning is constructed within sentences and across text as a whole'.

i. Quantitative Analysis of Language Skills:

Every unit of English Curriculum for Middle School: Revised Edition for Grade Six, the Workbook and Oxford English an International Approach Book One supplement learning outcomes comprises of multiple exercises and activities offering practice of language skills like reading, listening, speaking, writing, vocabulary and grammar. The following graph represents quantity of language tasks given in the curriculum;

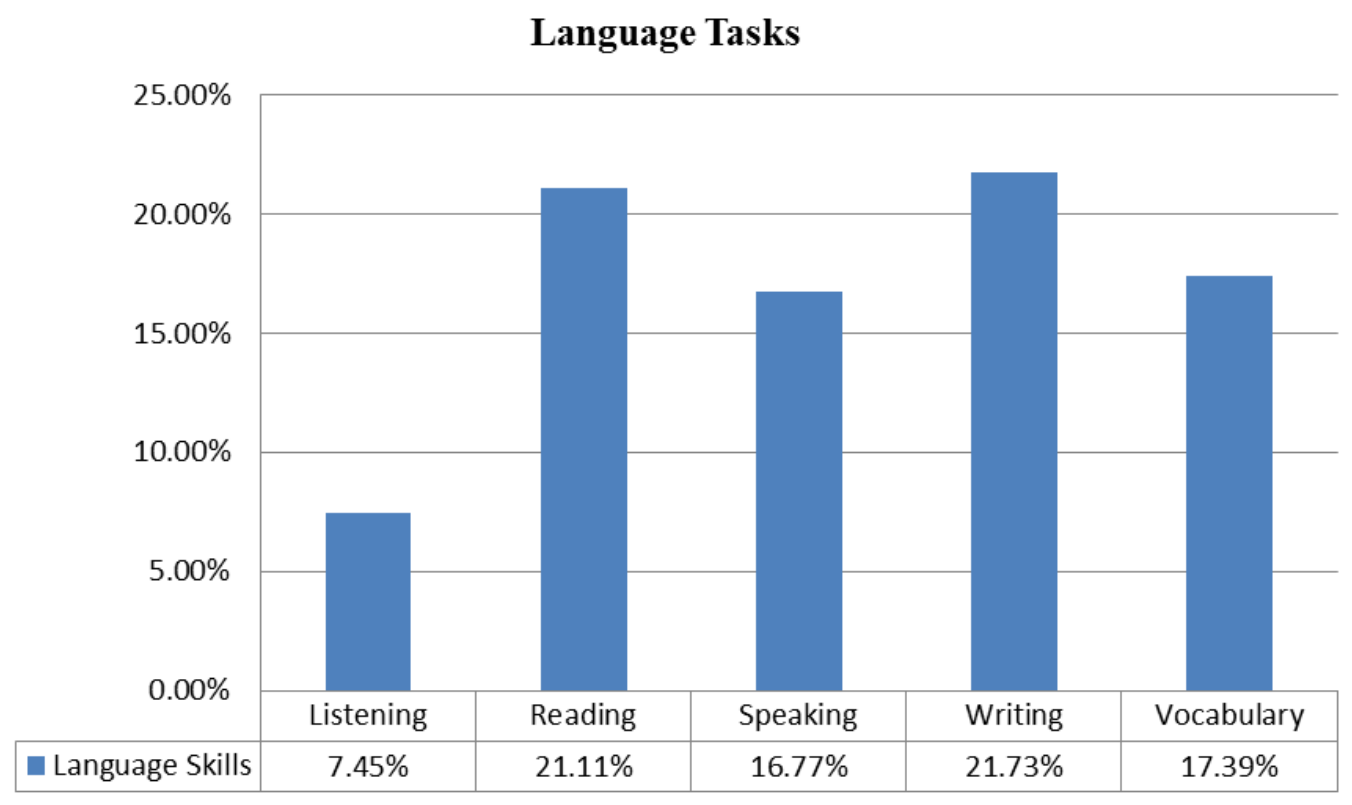

Figure 8. Language Skills in English Curriculum for Middle Schools 
Table 2. Frequency table of language tasks in English Curriculum

\begin{tabular}{|c|c|c|c|c|}
\hline Language Tasks & Frequency & Percent & Task Percent & Cumulative Percent \\
\hline Reading & 34 & 21.0 & 21.0 & 21.0 \\
Listening & 12 & 07.0 & 07.0 & 28.0 \\
Speaking & 27 & 17.0 & 17.0 & 45.0 \\
Writing & 35 & 22.0 & 22.0 & 67.0 \\
Vocabulary & 28 & 17.0 & 17.0 & 84.0 \\
Grammar & 25 & 16.0 & 16.0 & 100.0 \\
Pronunciation & 00 & 00.0 & 00.0 & \\
Total & 161 & 100.0 & 100.0 & \\
\hline
\end{tabular}

The representation of language tasks in (Table 2) English Curriculum for Middle School: Revised Edition for Grade Six, the Workbook and Oxford English an International Approach Book One show that reading with 34 tasks and writing skills with 35 tasks are more focused which are $21 \%$ and $22 \%$ respectively of all the language tasks. On the other hand, listening skills have 12 tasks which are 7\% of all the tasks of language skills. Speaking skills include 27 tasks which are $17 \%$ of the total. Listening and speaking skills are comparatively of less focus. The tasks regarding vocabulary include 28 tasks which share $17 \%$ of the language tasks whereas grammar tasks carve up with 25 tasks which are $16 \%$ of all the language tasks in the curriculum. Interestingly, pronunciation skills are totally ignored in the curriculum. It does not contain any task regarding learners' pronunciation.

\subsubsection{Composition and Presentation Skills}

\section{i. Curriculum helps acquiring a wide range of vocabulary.}

The vocabulary as in 'wordpool' and 'glossary' comprising almost 8 to 10 words collectively is given at the end of every topic and sub-topic. In addition, occurring of words in the text is highlighted by mentioning paragraph or line number of each occurrence in 'wordpool'. The vocabulary exercises given in the workbook also help learners in acquiring a wide range of vocabulary.

ii. Curriculum offers tasks for organizing and structuring effective writing style and sentence structure.

Curriculum also offers tasks such as, 'Make a Venn diagram comparing and contrasting Shabanu's and a student life' (p. 4), illustrate the difference between Shabanu's and a 
students' life through a composition. (p. 9), and 'write a carefully and thoughtfully, with varied linguistic and literary techniques, producing a story that interests and engages the reader' (p. 105) which help for organizing and structuring effective writing style and sentence structure.

iii. Curriculum includes tasks to work on diverse variety of forms.

Curriculum includes different tasks ranging from receptive skills (i.e. listening and reading), productive skills (i.e. writing and speaking), vocabulary, grammar and tasks related to different genres (e.g. myth, fiction, poetry, drama, prose, biography, autobiography and media like newspaper reports, TV, internet, film). Furthermore, varying tasks include writing a journal, interpretation of different topics, writing poetry, conducting debate and role play etc.

iv. Curriculum offers exercises for accurate punctuation.

Punctuation tasks are not given either in English Curriculum for Middle School: Revised Edition for Grade Six or Oxford English an International Approach Book One. Punctuation tasks are also not given in the workbook.

v. Curriculum offers exercises for correct spelling.

Exercises related to spellings are not given either in English Curriculum for Middle School: Revised Edition for Grade Six or Oxford English an International Approach Book One. Spelling tasks are also not given in the workbook.

vi. Curriculum helps promoting legible handwriting.

Curriculum does not offer any tasks to promote handwriting of the learners. There is no such task either in English Curriculum for Middle School: Revised Edition for Grade Six or Oxford English an International Approach Book One. Tasks to promote handwriting are also not given in the workbook.

\subsubsection{Practical Considerations}

i. The curriculum presents supplementary materials (tapes, visuals etc.)

Curriculum includes 'suggested ICT activities' which incorporates different websites (e.g. Edmodo, Bubble.us, Prezi, Voice Thread, Pixton and Pivostick animator). Tasks include, for example, 'create audio-recording (podcast) of poem at VoiceThread', and 'make mind maps using Bubble.us' etc.

\section{ii. The book addresses different learning styles and strategies.}

The course book addresses different learning styles and strategies as the examples include, Solo Work Activities, Group Activities, Brainstorming, and Critical Thinking etc.

iii. The objectives are specified explicitly in the course book.

The objectives are specified explicitly in the course book. For instance, identification and understanding of the main ideas, viewpoints, themes, and purposes in a text (curriculum targets) develops different ways of gathering organizing and shaping ideas using a range of 
planning formats and methods. Every unit of course book contains learning objectives in the form of Experience, Read and Create comprises of multiple exercises and activities offering practice of language skills like grammar, vocabulary, reading and writing, listening and speaking. The curriculum also includes learning objectives for every lesson in the course book.

\section{iv. Curriculum promotes critical thinking.}

Curriculum includes 'Suggested ICT Activities', and 'Cross Curricular Links' which offer varying activities to promote critical thinking, for instance, creating mind maps, creating stick figure story, 'links with Social Studies and Wild Life study in terms of identifying endangered animals and the reasons why they are endangered' (p. 8).Tasks regarding language skills also offer opportunities such as, 'writing creatively and thoughtfully, with varied linguistic and literary techniques, producing a story that interests and engages the reader' in order to promote critical thinking (p. 8).

\section{Conclusion}

The present study evaluates ESL Curriculum designed for Beaconhouse School System in Pakistan, in order to check its relevance with the devised objectives and textbooks. After the analysis it is observed that English Curriculum for Middle School: Revised Edition for Grade Six, the Workbook and Oxford English an International Approach Book One, according to the checklist, are meeting the criteria. There is a significant relationship between curriculum objectives and content of Oxford English an International Approach Book One and the Workbook. The learning of language has specifications which are fulfilled in course books, so for as listening skills and pronunciation is not much focused. Moreover, there is no organization in the sequence of difficulty in introducing new vocabulary items which are randomly given in two sections (i.e. wordpool and glossary) while, grammar activities are designed in a logical sequence.

In addition, curriculum is meeting the criteria of checklist. The analysis of the data reveals that four language skills are in a practical yet enquiry based framework. Secondly, content introduces global contexts and issues to encourage critical thinking, self-discovery and problem-solving. Thirdly, cross curricular links are provided to help students understand the relevance of their learning. Fourthly, Teacher's Guides link activities to concepts and provide worksheets to extend learning and understanding. Fifthly, bright and colorful design is thoroughly student-friendly, increasing motivation, and sixthly, the content is truly international, including fiction and non-fiction texts sourced from all over the world. The course books, thus, meet most of the objectives of English Curriculum of Beaconhouse School System (BSS) though the course books and the curriculum require improvement in the content. Whereas, course books do not meet some of the curriculum objectives including activities/exercises related to punctuation, spellings and handwriting. According to the researchers, the content of the curriculum and course books should be modified to devise activities for learners' pronunciation, spellings, legible handwriting, punctuation, and focused listening skills. 


\section{References}

Burki, S. J. (1986). Pakistan: A Nation in the Making. Karachi: Oxford University Press.

Crystal, D. (1997). English as a global language. Cambridge: Cambridge University Press.

Cunningsworth, A. (1995). Choosing your Textbook. London: Macmillan: Heinemann

Demir, Y., \& Ertas A. (2014). A Suggested Eclectic Checklist for ELT Coursebook Evaluation, The Reading Matrix.

Ellis, Rod. (1997). The empirical evaluation of language teaching materials. ELT Journal, 51(1), pp. 36-42.

Flowerdew, J., \& Peacock, M. (Eds.). (2001). Research perspectives on English for academic purposes. Cambridge: CUP.

Government of Pakistan, Finance Division. (2011-11). Economic Survey of Pakistan. Islamabad: Ministry of Education.

Holliday, A. (1994). Appropriate Methodology and Social Context. Cambridge: Cambridge University Press.

Iqbal, M. (2012). Public versus Private Secondary Schools: A Qualitative Comparison. Journal of Research and Reflections in Education, 6(1), pp 40 -49.

Littlejohn, A. (1998). The analysis of language teaching materials: Inside the Trojan Horse, in B. Tomlinson (ed.), Materials development in language teaching. Cambridge: CUP, pp.190-216.

Litz, D. R. A. (2005). Textbook evaluation and ELT management: a South Korean case study. Asian EFL Journal.

Lauder, A. (2008). The status and function of English in Indonesia: A review of key factors. Makara, Social Humaniora, 12(1), pp. 9-20.

Mahmood, K. (2006). The process of textbook approval: A critical analysis. Bulletin of Education \& Research, 28(1), pp. 1-22. Retrieved November, 2011 from: http://pu.edu.pk/images/journal/ier/previous_pdf/1-Paper_textbooks\%5B\%5D.pdf

Majeed, R. (2012). Humanizing English Textbooks Evaluation at Higher Secondary Level in Punjab. Unpublished M.Phil. thesis, Government College University, Faisalabad, Pakistan.

Maleki, Hasan, (2009), curriculum planning as a practical guidance. Tehran: Payam-eAndishe Publications.

Nunan, D. (1993). Task-based syllabus design: Selecting, grading and sequencing tasks. In G. Crookes, \& S. M. Gass (Eds.), Tasks in a pedagogical context. Cleveland, UK: Multilingual Matters.

Rahman, T. (2003). Language Education and Culture. Oxford University Press. pp. 98, 89, 65. 
Rahman, T. (2009). Language ideology, identity and the co-modification of language in the call centers of Pakistan. Language in Society, 38(2), pp. 233-258.

Redford, R. (2011). Oxford English an International Approach Book 1. Oxford University Press, Karachi.

Riazi, A. M. (2003). What Textbook Evaluation Schemes Tel Us? A Study of the Textbook Evaluation Schemes of Three Decades. In W.A. Renanda. (ed.), Methodology and Materials Design in Language Teaching. Singapore: Seameo Regional Center, pp. 52-68.

Sheldon, L. E. (1988). Evaluating ELT textbooks and materials. ELT Journal, 42, 237-246.

Tucker, C. A. (1975). Evaluating beginning textbooks. English Teaching Forum, 13, 335-361.

Ur, P. (1996). A Course in Language Teaching. Cambridge: Cambridge University Press.

\section{Appendix}

Appendix 1. The ELT Curriculum Evaluation Checklist

\begin{tabular}{|c|c|c|c|c|c|c|}
\hline \multicolumn{7}{|c|}{ Checklist for Curriculum Evaluation Grade - Six } \\
\hline & \multicolumn{6}{|c|}{ Scores } \\
\hline Subjects and Contents & NA & 0 & 1 & 2 & 3 & 4 \\
\hline \multicolumn{7}{|l|}{$\begin{array}{l}\text { The content serves as a window into learning about } \\
\text { the target language culture (American, British etc.) }\end{array}$} \\
\hline \multicolumn{7}{|l|}{$\begin{array}{l}\text { The subject and content of the course book is } \\
\text { motivating. }\end{array}$} \\
\hline \multicolumn{7}{|l|}{$\begin{array}{l}\text { There is sufficient variety in the subject and content } \\
\text { of the course book. }\end{array}$} \\
\hline \multicolumn{7}{|l|}{ The thematic content is culturally appropriate. } \\
\hline \multicolumn{7}{|l|}{$\begin{array}{l}\text { There is a relationship between the content of the } \\
\text { course book and real-life situations (society) }\end{array}$} \\
\hline \multicolumn{7}{|l|}{$\begin{array}{l}\text { The topics and texts in the course book include } \\
\text { elements from both local and target culture. }\end{array}$} \\
\hline \multicolumn{7}{|l|}{$\begin{array}{l}\text { Curriculum focuses on individual cultural identities } \\
\text { and on the importance of one's own language and } \\
\text { culture. }\end{array}$} \\
\hline \multicolumn{7}{|l|}{$\begin{array}{l}\text { Curriculum helps in recognition of interdisciplinary } \\
\text { links with other subjects. }\end{array}$} \\
\hline \multicolumn{7}{|l|}{$\begin{array}{l}\text { Curriculum expresses facts and ideas about the } \\
\text { world to promote personal understanding and } \\
\text { global perspective. }\end{array}$} \\
\hline \multicolumn{7}{|l|}{ Sub-skills and Skills } \\
\hline \multicolumn{7}{|l|}{ Reading } \\
\hline There are exercises and tasks for improving reading & & & & & & \\
\hline
\end{tabular}




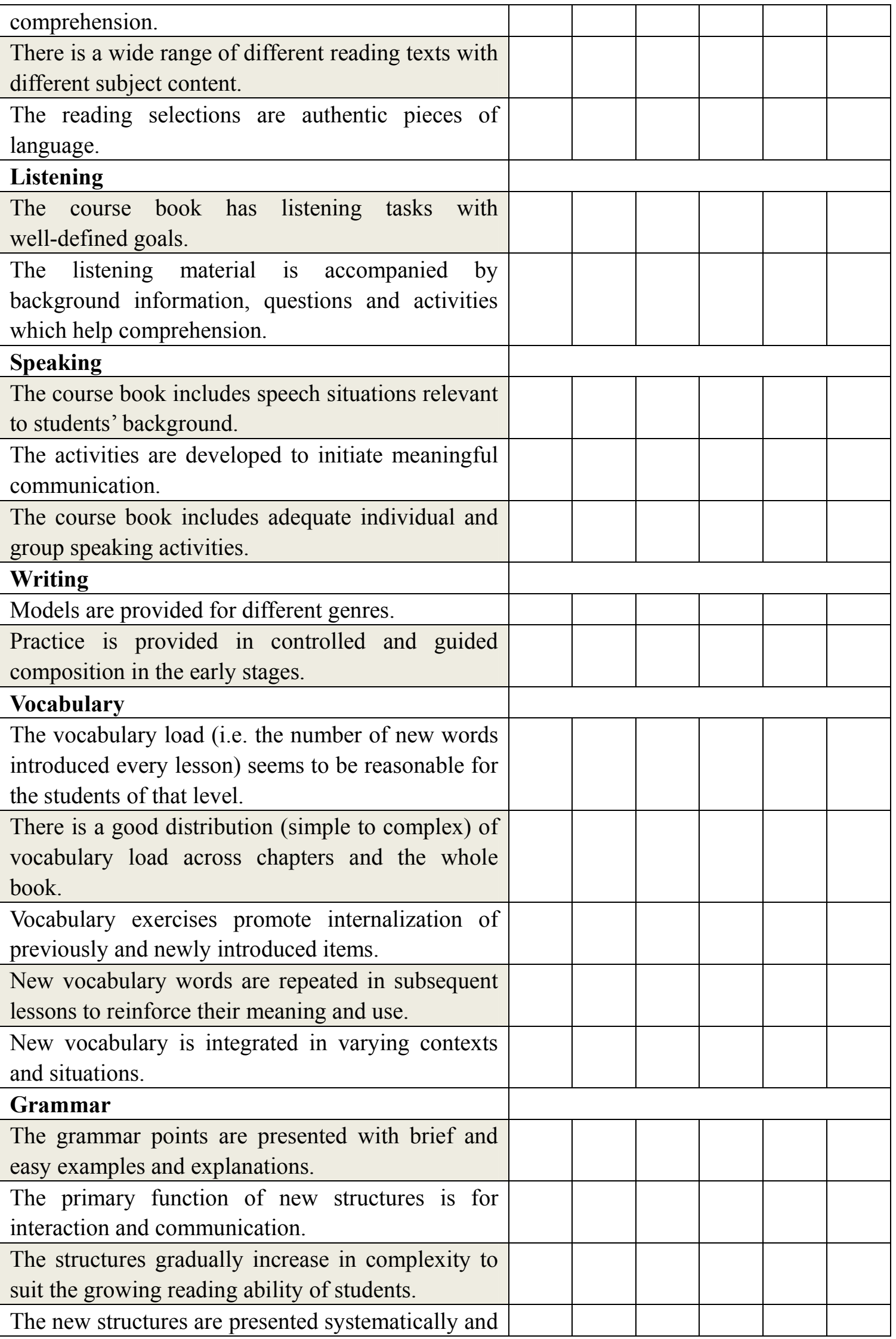




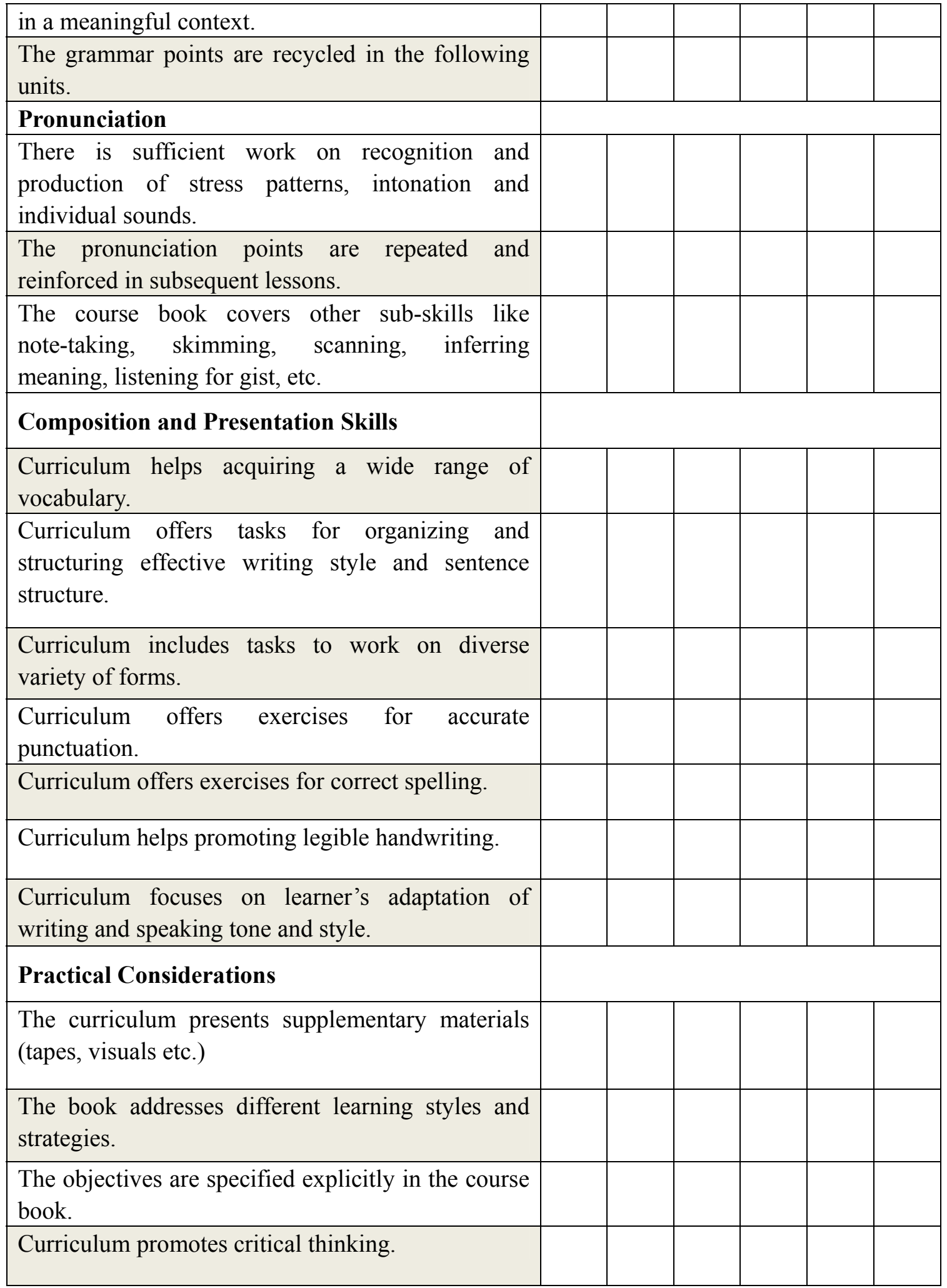




\section{Ml Macrothink \\ International Journal of English Language Education \\ ISSN 2325-0887 2015, Vol. 3, No. 2}

\section{Copyright Disclaimer}

Copyright for this article is retained by the author(s), with first publication rights granted to the journal.

This is an open-access article distributed under the terms and conditions of the Creative Commons Attribution license (http://creativecommons.org/licenses/by/3.0/). 